\title{
Preliminary Observations on Phagocytosis in the Peripheral Blood of Sockeye Salmon (Oncorhynchus nerka)
}

\author{
Gordon R. BeLL \\ Department of the Environment, Fisheries and Marine Service, Pacific Biological Station, \\ Nanaimo, B.C., V9R 5K6, Canada
}

\begin{abstract}
The ability of circulating leucocytes of non-immunized, cultured sockeye salmon to phagocytize bacteria in the blood stream was examined using two techniques; cannulation of the dorsal aorta (for the injection of bacteria and for blood sampling) and intracardiac injection. With the first technique no phagocytosis was observed in the peripheral blood but there was a rapid uptake of bacteria that was particularly impressive in the kidney. Some phagocytosis in the blood stream, mostly by polymorphonuclear leucocytes, was demonstrated using the second technique but there was the possibility that these phagocytes had actually drained from the renal portal system following caudal blood sampling. The results so far confirm the observations of others that phagocytosis in the peripheral blood of salmonids is insignificant or non-existent.
\end{abstract}

\section{Introduction}

When tissues or blood of vertebrates are invaded by bacteria the invading cells are engulfed by ameboid cells, leucocytes of the granulocyte series and macrophages, referred to generally as phagocytes. In the "inflammatory response" or orderly reaction of tissue to injury, including invasion, the phagocytes primarily responsible for ingesting bacteria are the polymorphonuclear neutrophils, and those that scavenge necrotic tissue of cellular debris are the macrophages. In the acute inflammatory response neutrophils are followed by macrophages. The entire inflammatory response is a very complex process necessary for the survival of the host by providing a defence reaction or mechanism against an injurious agent (referred to as an irritant) such as a microorganism.

Since there are fairly recent and comprehensive bibliographies and reviews of defence, or better, protective mechanisms in fish by Finn (1970) and Lewis et al. (1970), little more need be said. Around the turn of the century Metchnikoff and others in France and Italy observed in vivo phagocytosis of certain bacteria and foreign blood cells in several species of fish. But many influential medical pathologists of the day felt that phagocytosis was a relatively unimportant protective mechanism even in homeothermic animals, which might explain why the subject was generally ignored for some time. Post (1963) found that "demonstration of phagocytosis proved to be much more difficult than at first expected," and he was unable to observe phagocytosis in the blood or peritoneum of immunized and nonimmunized rainbow trout that had been injected intracardially and intraperitoneally, respectively, with suspensions of Aeromonas hydrophila. Nor could he demonstrate phagocytosis in vivo in blood from immunized and non-immunized trout. Phagocytosis did occur in the peritoneum of specially pre-treated fish. In some contrast, Klontz and Yasutake (1966) found that necrotic material but not bacteria was ingested by macrophages and neutrophils $32 \mathrm{hr}$ after injection with Aeromonas salmonicida. Finn and Nielsen (1971) found that the sequence of events in the inflammatory response of rainbow trout was comparable to 
that of mammals when they injected heatkilled suspensions of Staphylococcus aureus intramuscularly, intraperitoneally and periorbitally. The response was, however, slower and weaker than in mice. They also found that first the polymorphonuclear leucocytes and then the macrophages were actively phagocytic.

What little work has been done on phagocytosis in salmonids was mostly incidental to other studies and almost nothing has been done on phagocytosis in peripheral blood. Hatai (1972b), however, has done some very interesting and useful work on phagocytosis in the blood of the eel, Anguilla japonica. The purpose of the preliminary work reported here was to gain some further understanding of protective mechanisms of healthy salmon, and to see if function as well as structure were consistent with the names commonly given to certain leucocytes. Experiments were conducted to see which, if any, of the circulating leucocytes could phagocytize bacteria.

\section{Materials and Methods}

Fish. Cultured, non-immunized juvenile sockeye salmon of various sizes held in fresh water at several temperatures were used for experimentation. Fish were not fed for $48 \mathrm{hr}$ before use.

Bacterial irritant. Lactobacillus brevis was selected as the irritant because no fish pathogen available had the desired size, shape, uniformity and distinctiveness of morphology, and yet could be readily stained by conventional blood stains. Cocci or cocco-bacilli, for example, are often not readily distinguishable from tissue debris or intracellular components. Heat-killed suspensions of cells in physiological saline were prepared by conventional methods as for vaccines.

The cell suspension was administered either by intracardiac injection or via a cannula in the dorsal aorta (Smith and Bell 1964). If the former method were used, blood samples were taken by severing the caudal fin; if the latter, blood was simply removed from the cannula without disturbing the fish. Direct intravascular injection and withdrawal of samples are probably the best ways to avoid contamination of the sample by phagocytes of the penetrated tissue, i.e., by histogeneous phagocytes.

The anesthetic used was tricaine methanesulphonate at $1: 12,000$.

Blood smears were flooded for 6 min with a commercial Giemsa reagent (Fisher Scientific Co., Cat. No. SO-G-28), then an equal volume of distilled water was added and the staining continued for 3 more min. This stain differentiated the cell types clearly and also stained the bacteria readily.

\section{Results}

Injection via cannula

As demonstrated by at least 10 trials of this technique phagocytosis by leucocytes free in the blood stream is almost non-existent. Only one or two unidentified mononuclear leucocytes which had apparently ingested bacteria were observed.

Bacteria which at 15 min post injection were in a ratio of $4: 1$ ( $345 \mathrm{~g}$ fish) and 2:1 ( $509 \mathrm{~g}$ fish) to erythrocytes had decreased by one-half or more in $30 \mathrm{~min}$, and had almost disappeared by $120 \mathrm{~min}$ and $75 \mathrm{~min}$, respectively. The ambient water temperature was $5^{\circ} \mathrm{C}$ (February). Occasional clumps of cells persisted in the blood stream (or were released from the tissues) for several hours. Examination of tissue imprints suggested that the mid-kidney (no attempt was made to distinguish between functional areas) contained particularly high numbers of apparently phagocytized and free bacteria: relatively greater than the spleen, heart, and least of all the liver. Quantitative comparisons were not made. Much the same pattern occurred when six ca. $150 \mathrm{~g}$ fish held at $12^{\circ} \mathrm{C}$ were used, but most bacterial cells had disappeared from the blood in $15 \mathrm{~min}$.

Injection via the heart

Three hours after two ca. $18 \mathrm{~cm}$ sockeye held at $17^{\circ} \mathrm{C}$ (July) had been injected intra- 
cardially with L. brevis, phagocytes were observed on smears of caudal blood. Six of these phagocytes are shown in Fig. 1, each centered in a different field, also containing erythrocytes. L. brevis is seen as a dark rod or rods.

\section{Discussion and Conclusions}

These results suggest that phagocytosis by leucocytes circulating in the bloodstream of salmon is probably of little or no significance in removing invading bacteria. Substantial phagocytosis, possibly associated with physical trapping of bacteria, appeared to occur principally in the kidney. But some phagocytes were seen in the heart, spleen, and rarely, the liver. Claims of phagocytosis must be made with caution, however, because it is almost

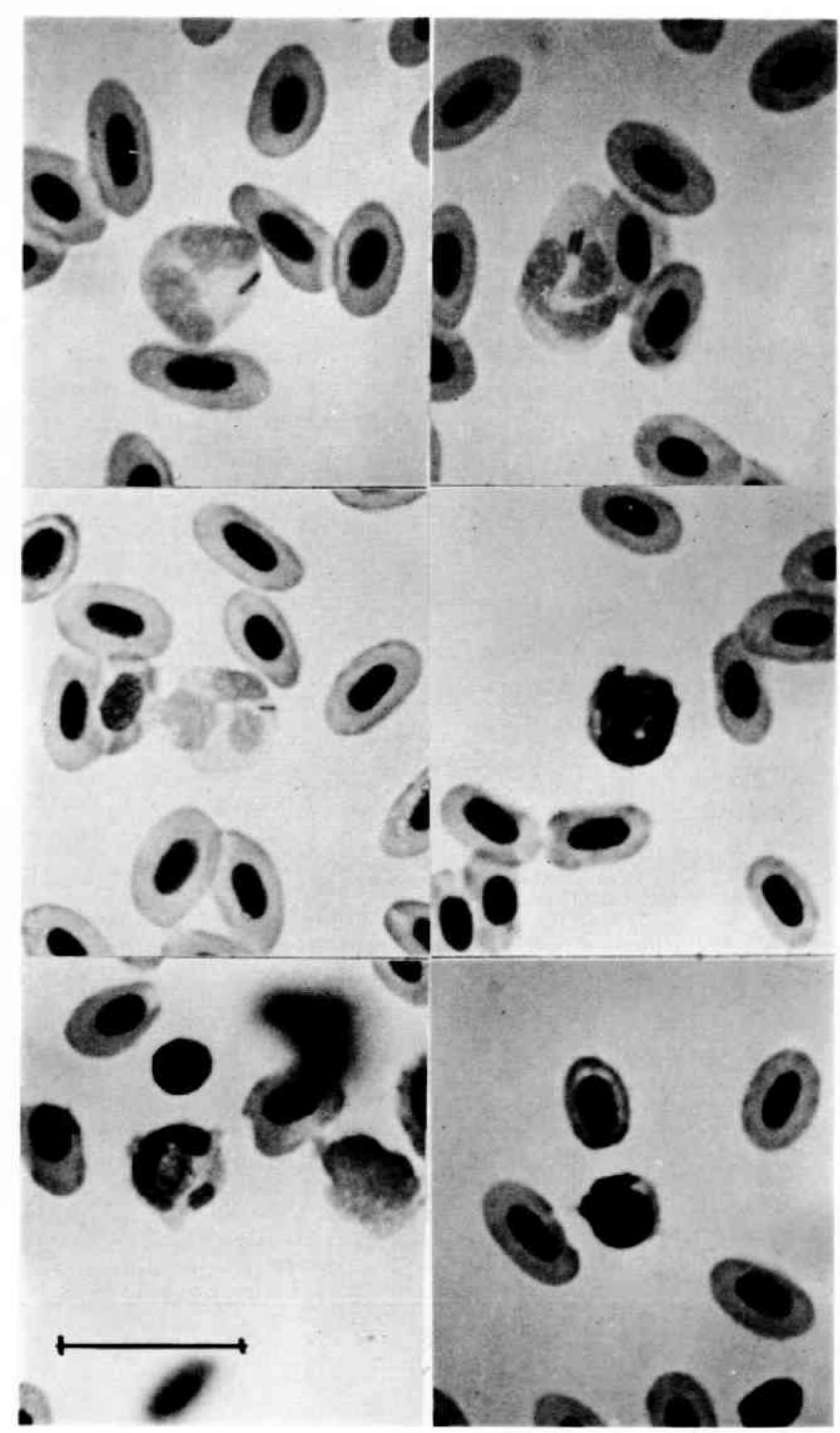

FIGURE 1. Giemsa stained blood cells on smears obtained by severing the caudal fin. Phagocytes containing the rods of intravascularly injected $L$. brevis are in the center of each frame. Erythrocytes show as nucleated, ovoid cells. The bar in the lower lefthand corner represents $25 \mu \mathrm{m}$. 
impossible in a mass of tissue cells such as in the kidney to be sure whether bacteria are in, or passively on, leucocytes. This problem was one reason for beginning the studies by examining blood rather than tissue for phagocytosis.

Some phagocytosis did apparently occur in the blood stream but this relatively rare event was possibly related to the site of blood sampling rather than to the route of administration of bacteria, or to higher temperature. The phagocytes shown in Fig. 1 could have drained from the renal portal system (Smith and Bell 1975) where the phagocytosis actually took place. This possibility could explain the apparent contradiction to the work of Post (1963) who was unable to demonstrate phagocytosis in the peripheral blood of trout. The necessity of phagocytes (i.e., leucocytes containing ingested foreign matter) to act on a surface (Boyd 1970) also suggests that observations of them in the blood stream do not necessarily imply that phagocytosis took place there.

Apart from the phagocyte in the bottom right frame of Fig. 1, all seem to be polymorphonuclear leucocytes, in keeping with the structural and functional criteria usually assigned to their mammalian counterparts. The naming of the remaining phagocyte will be left to those more competent (or foolhardy), lest I add more confusion to an already bewildering subject, the nomenclature of fish blood cells. But it is tentatively suggested that the cell is a monocyte. Indeed, Jakowska (1956) issued a still timely note of caution about applying medical terminology to the naming of morphologically similar fish blood cells. A name based on morphological similarity alone may make unwarranted implications about the origin and function of the cell.

Large numbers of bacteria can be rapidly removed from the peripheral blood and it would be interesting to know the comparative distribution of the microorganisms between and within tissues of immunized and nonimmunized salmon. It is hoped to examine this subject much as Hatai (1972a and b) did with eels, or with the use of killed bacterial cells labelled with some detectable substance.

\section{Acknowledgements}

I would like to thank G. E. Hoskins and G. S. Traxler for their assistance during some of this work, and Dr. L. Margolis for useful comments on the manuscript.

\section{Rferences}

Boyd, W. 1970. A textbook of pathology. Lea and Febriger, Philadelphia. 1464 p.

Finn, J. P. 1970. The protective mechanisms in diseases of fish. Vet. Bull. 40 (12), 873-886.

Finn, J. P., and N. O. Nielsen. 1971. The inflammatory response of rainbow trout. J. Fish Biol. 3, 463-478.

Hatai, K. 1972a. Studies on the fate of intravascularly injected bacteria in fish-I. Changes in number of cells of Aeromonas liquefaciens in the blood, liver and kidney of the eel. Fish. Pathol. 7 (1), 26-33.

Hatai, K. 1972b. Studies on the fate of intravascularly injected bacteria in fish-II. Changes in number and composition of leucocytes in the blood of the eel. Fish Pathol. 7 (1), 34-43.

Jakowska, S. 1956. Morphologie et nomenclature des cellules du sang des Téléostéens. Revue Hémat. 11 (5), 519-539.

Klontz, G. W., and W. T. Yasutake. 1966. Bacterial diseases of the Salmonidae in the Western U.S. Am. J. Vet. Res. 27, 1455-1460.

Lewis, D. H., G. W. Klontz, S. McConnell and L. C. Grumbles. 1970: Infectious diseases and host response of marine fish, a partially annotated bibliography. Texas $\mathbf{A}$ and $\mathbf{M}$ University, Sea Grant Publ. No. TAMU-SG-71-401, 104 p.

Post, G. 1963. The immune response of rainbow trout to Aermonas hydrophila. Publ. No. 63-7, Utah State Department of Fish and Game. 82 p.

Smith, L. S., and G. R. Bell. 1964. A technique for prolonged blood sampling in free-swimming salmon J. Fish. Res. Board Can. 21, 711-717.

Smith, L. S., and G. R. Bell. 1975. A practical guide to the anatomy and physiology of Pacific salmon. Fish Mar. Serv. Misc. Spec. Publ. 27. I4 P.

\section{Discussion}

T. Sano: Besides neutrophil leucocytes, monocytes also appear, don't they? 
G. Bell: I think that the phagocyte in the lower right frame of Fig. 1 is probably a monocyte, at least according to the illustrations of Yuki (Bull. Fac. Fish. Hokkaido Univ. 8: 36, 1957). However, many authors do not include the name monocyte in their list of blood cell types in fishes, and Klontz (Symp. Zool. Soc. Lond. No. 30, 89, 1972) stated that some workers think that the hematogenous macrophage should be called a monocyte. Katz (Ph.D. Thesis, U. of Wash., 1949) remarked that the "monocyte is perhaps the most difficult cell to classify" and monocytes "are hard to differentiate from the larger lymphocytes and immature neutrophiles" in coho salmon. Jakowska (Revue Hemat. 11: 519, 1956) who gave special attention to "le problème du monocyte" felt that Katz's description of a monocyte was more appropriate to that of a small hemoblast commonly found in the peripheral blood of fish during active hematopoiesis. These cells are phagocytic, as is the mammalian monocyte.

In 1964 Klontz and colleagues (unpublished) issued a plea for a standardized terminology and technology with respect to the hematology of rainbow trout-let it be salmonids generally. Unfortunately, the plea has gone unanswered and we are still confronted with subjectively applied terminology, often with inadequate descriptions. We urgently need an atlas of cellular hematology of salmonids (with photographs, drawings and written descriptions) so that there can be a standardization, if not agreement, on terminology. Perhaps this is a naive suggestion, considering the struggles of medical hematologists. 